\title{
Effect of Prior Infusion of Exogenous Bonito Insulin on Glucose-Induced Insulin Release in Man
}

\author{
Hisako OHGAWARA, Kazuo SUZUKI AND KINORI KOSAKA* \\ Department of Internal Medicine, \\ Tokyo Women's Medical College, Tokyo and \\ *The Third Department of Internal Medicine, \\ Faculty of Medicine, University of Tokyo, Tokyo
}

\section{Synopsis}

\begin{abstract}
In order to investigate a possible short feedback mechanism of insulin secretion, the effect of prior infusion of bonito insulin upon glucose-induced insulin secretion in man was studied. The increase in plasma insulin after intravenous injection of a glucose solution was analysed under prior sustaining infusion of bonito insulin at the concentration of $12 \mathrm{mU} / 0.5 \mathrm{ml} / \mathrm{min}$ and $6 \mathrm{mU} / 0.5 \mathrm{ml} / \mathrm{min}$. These concentrations of bonito insulin were shown to have had no effect on the blood sugar levels, nor on the basal insulin levels. After the prior eight hour infusion of exogenous insulin, the increase in glucoseinduced insulin secretion was significantly smaller than that produced after infusion of saline as a control. The magnitude of the inhibition in plasma insulin elevation was more remarkable at the higher dose of insulin. The level of blood sugar after glucose injection shown no significant change.

The half-life of immunoreactive insulin in plasma was determined after prior infusion of bonito insulin or saline for three hours. There was not tendency to any difference in $\mathrm{T} 1 / 2$ between saline treated subjects and subjects who had received the rapid injection of porcine insulin prior to the infusion of bonito insulin.
\end{abstract}

The possibility of a feedback inhibition of insulin release by insulin itself has been an object of controversy. Although there have been several reports suggesting a direct feedback inhibition of insulin by insulin (Best \& Haist, 1941; Sodoyez et al., 1964; Logothetopoulos et al., 1965; Sodoyez et al., 1969; Chu \& Goodner, 1968; Hellman \& Lernmark, 1969; Iversen \& Miles, 1971; Hahn \& Micheal, 1971) some workers found no inhibition (Grodsky et al., 1968b; Malaisse et al., 1967; Sando et al., 1970) However, in man, it has not yet been documented whether insulin secretion is influenced by the blood level of insulin. In order to investigate any presence of a feedback mechanism of insulin secretion, the effect of prior infusion of bonito insulin upon glucose-induced insulin secretion in man

Received for publication May 11, 1973, was studied.

Bonito insulin is known to differ from mammalian insulin in immunological specificity, but possesses comparable biological activity to porcine and human insulin (Sando et al., 1970; Berson \& Yalow, 1959; Grodsky, 1965; Falkmar \& Whson, 1967; Samols \& Ryder, 1961; Yalow \& Berson, 1964) Thus, it is expected that circulating bonito insulin can be immunologically distinguished from endogenous insulin when administered to man.

\section{Materials and Methods}

Effect of prior infusion of bonito insulin on glucoseinduced insulin release

15 healthy non-obese male volunteers ranging in age from 19 to 30 , were selected for this study, in some cases, studies were repeated in the same subject. 
All subjects continued to take their regular diet, but on the night before the study they were instructed to take no solid food after the evening meal and no liquids except water. No smoking was allowed on the day of the test.

Indwelling needles were inserted in one antecubital vein of each arm, one for infusions and the other for blood sampling. The needle for sampling was kept patent with heparin saline. Bonito insulin (Shimizu Seiyaku Co. Japan $18.4 \mathrm{IU} / \mathrm{mg}$ ) was infused for 8 , 3 , or $1 \mathrm{hr}$ at a dose of $6 \mathrm{mU} / 0.5 \mathrm{ml} / \mathrm{min}$ or $12 \mathrm{mU} /$ $0.5 \mathrm{ml} / \mathrm{min}$ and a constant flow rate of $0.5 \mathrm{ml}$ per minute was kept by use of an infusion pump.

As a control saline was infused at a rate of $0.5 \mathrm{ml}$ min. Then, a $40 \mathrm{~g}$ per $100 \mathrm{~m} l$ solution of glucose was administrated intravenously for 60 minutes, $0.5 \mathrm{~m} /$ / min, immediately following the infusion of insulin or saline.

Blood was collected at one hour intervals during the infusion of insulin or saline, and at $0,2,4,6,8$, $10,15,20,30,60,90,120$ and $180 \mathrm{~min}$ after initiation of glucose infusion. Heparinized blood samples were kept at $4^{\circ} \mathrm{C}$ and centrifused within three hours. Plasma was stored forzen at $-20^{\circ} \mathrm{C}$. Plasma glucose was determined in duplicate by the method of Hagedorn-Jensen (1923). The serum was analysed for IRI by the double antibody radioimmunoassay modified from Morgan and Lazarow (Morgan \&
Lazarow, 1963; Samols \& Bilkus, 1964). Blood samples were measured for endogenous insulin using porcine insulin as the reference standard.

Effect of prior infusion of honito insulin on disappearance rate of porcine insulin, as immunoreactive insulin (Orskov \& Christensen, 1969) which was rapidly injected

Three subjects served as their own control, bonito insulin was infused at a dose of $12 \mathrm{mU} / \mathrm{min}$ at a constant flow rate of $0.5 \mathrm{~m} l$ per minute for three hours; this was followed by $3 \mathrm{U}$ of porcine insulin injected rapidly into the antecubital vein. More than one week later, the subject was restudied except a saline infusion was substituted for the constant infusion of bonito insuiin. Blood was taken at $-3,-2,-1 \mathrm{hr}$ and $0,2,4,8,10,15,20,30$, and $60 \mathrm{~min}$.

\section{Results}

The levels of blood sugar and insulin, analysed by use of porcine insulin as a standard reference, did not change throughout the infusion of bonito insulin and physiological saline (Fig. 1).

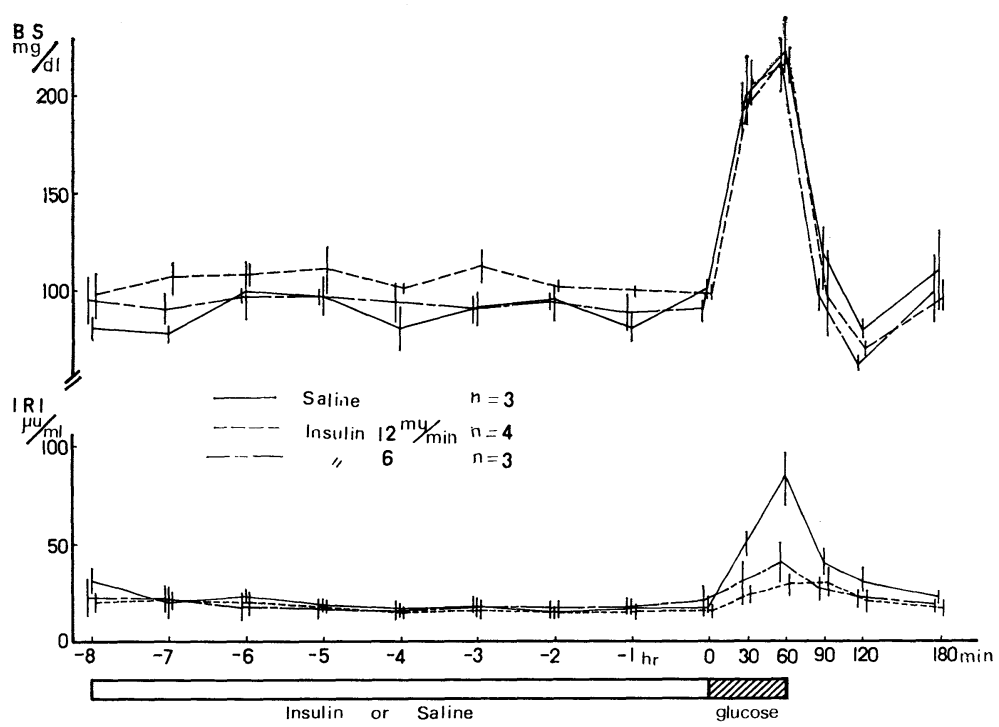

Fig. 1. Effect of prior infusion of bonito insulin on endogenous in sulin response to intravenous glucose administration. Bonito insulin was infused for $8 \mathrm{hr}$ at a dose of $6 \mathrm{mU} / \mathrm{min},(--)$ ) or $12 \mathrm{mU} / \mathrm{min}(--)_{-(-)}$at a constant flow rate of $0.5 \mathrm{ml}$ per min. As a control, saline (- was infused at a rate of $0.5 \mathrm{ml} / \mathrm{min}$. Then, a $40 \mathrm{~g}$ per $100 \mathrm{~m} l$ solution of glucose was administrated intravenously for $60 \mathrm{~min}, 0.5 \mathrm{ml} / \mathrm{min}$, immediately following the infusion of insulin or saline. Mean \pm S.E, 
In three groups which received $12 \mathrm{mU} / \mathrm{min}$, $6 \mathrm{mU} / \mathrm{min}$ of insulin and saline for $8 \mathrm{hr}$, blood sugar during the glucose load increased, reaching peak values $224 \pm 18.4,219 \pm 19.1$, and $218 \pm 18.4 \mathrm{mg}$ per $100 \mathrm{ml}$ at $60 \mathrm{~min}$. Values fell to a nadir at $120 \mathrm{~min}$ and rose again at $180 \mathrm{~min}$. The peak values were not significantly different, among the three groups. The mean peak levels of plasma IRI at $60 \mathrm{~min}$ after initiation of glucose decreased significantly $(\mathrm{p}<0.05)$ from $86 \pm 18.2 \mu \mathrm{U} / \mathrm{m} l$ in the group pretreated with saline to $30 \pm 5.1$ $\mu \mathrm{U} / \mathrm{m} l$ in the group pretreated with bonito insulin at a dose of $12 \mathrm{mU} / \mathrm{min}$. The IRI response of the group at a dose of $6 \mathrm{mU} / \mathrm{min}$ of bonito insulin was larger in magnitude than that of the group at the larger dose (Fig. 1).

As shown in Figure 2, mean blood sugar concentrations at $60 \mathrm{~min}$ after initiation of glucose were not significantly different in three groups which received $12 \mathrm{mU} / \mathrm{min}$ of insulin for $3 \mathrm{hr}$, for $1 \mathrm{hr}$ and saline for $1 \mathrm{hr}$.

After a period of three $\mathrm{hr}$ during which bonito insulin was infused at a dose of 12 $\mathrm{mU} / \mathrm{min}$, the insulin response to intravenous

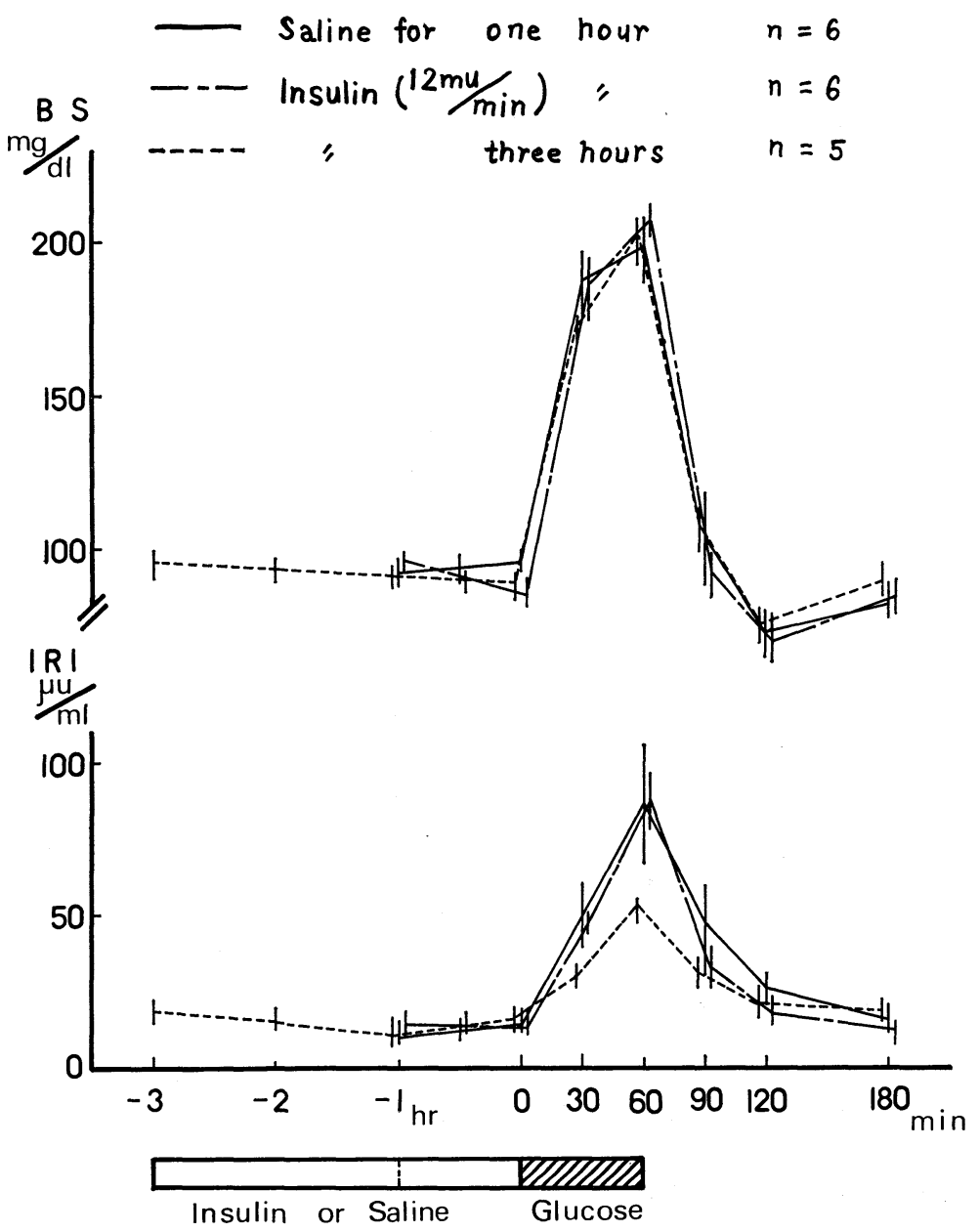

Fig. 2. Effect of prior infusion of bonito insulin on endogenous insulin response to intravenous glucose administration. Bonito insulin was infused for one and three hours at a dose of $12 \mathrm{mU} / \mathrm{min}$. Legends same as in Figure 1 , 


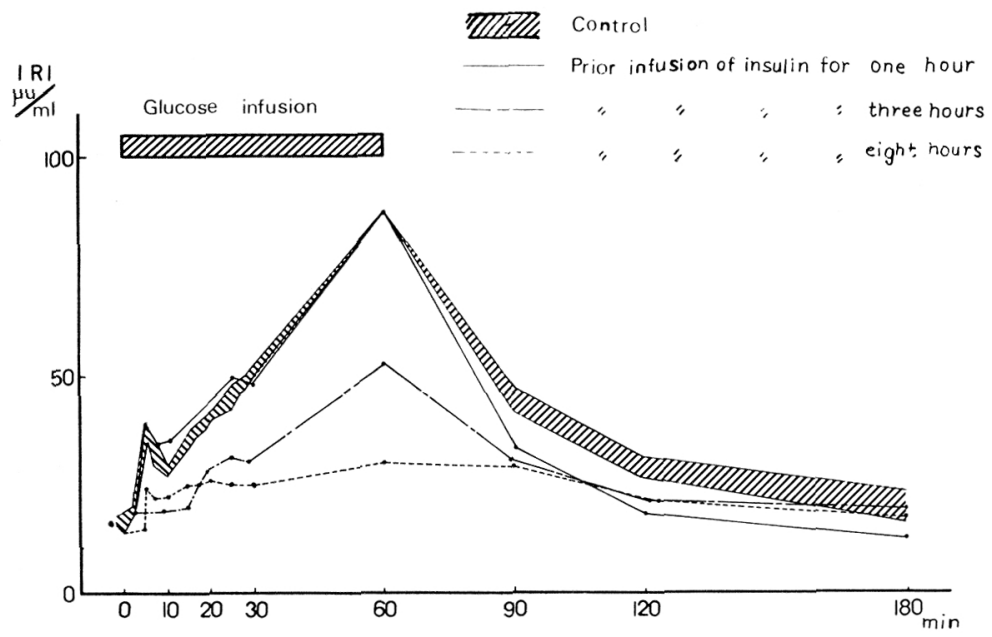

Fig. 3. Endogenous insulin response to intravenous glucose administration after exogenous insulin infusions. Bonito insulin was infused at a dose of $12 \mathrm{mU} / \mathrm{min}$ for one, three and eitht hours periods. Legend same as in Figure 1. and 2.

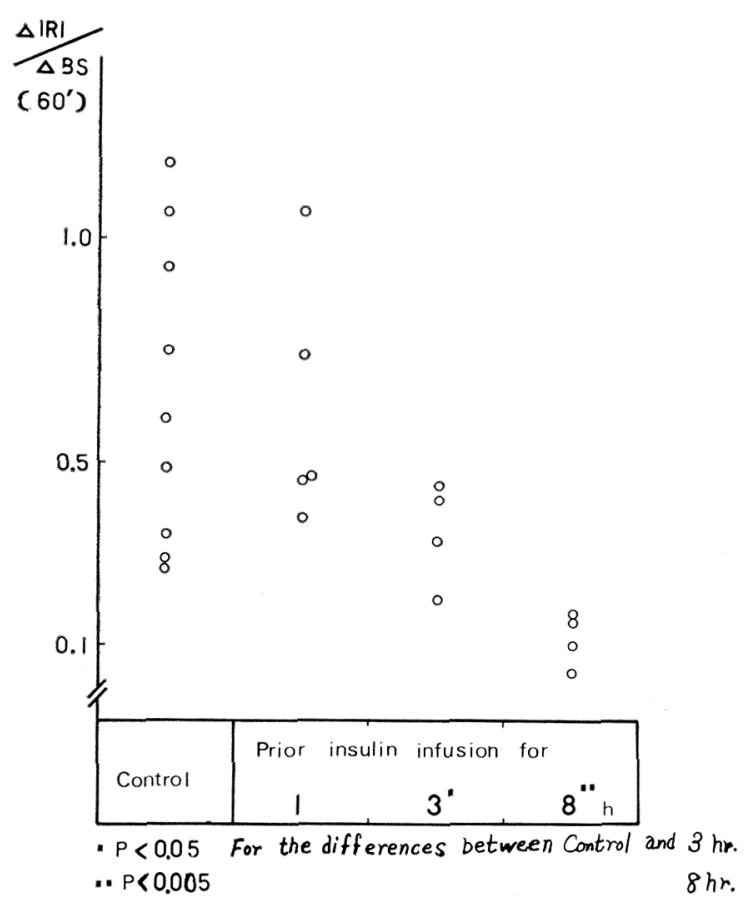

Fig. 4. The insulinogenic index ( $\triangle \mathrm{IRI} / \Delta \mathrm{BS})$ at 60 min after glucose administration. A control group was compared with groups given an insulin infusion at a dose of $12 \mathrm{mU} / \mathrm{min}$ during one, three, and eight hr. glucose injection at $60 \mathrm{~min}$ was smaller in magnitude than after the infusion of saline $(52 \pm 3.0 \mu \mathrm{U} / \mathrm{m} l$ versus $86 \pm 19.8 \mu \mathrm{U} / \mathrm{m} l, \mathrm{p}<$ 0.05 ). When the period of prior infusion of bonito insulin was shortened to one hour, insulin response to glucose was not significantly different from the control group $(87 \pm 9.3 \mu \mathrm{U} / \mathrm{m} l$ versus $86 \pm 19.8$ of the saline experiment). The mean serum IRI reponses to continuous glucose administration are shown in Figure 3. Bonito insulin was previously infused at a dose of $12 \mathrm{mU} / \mathrm{min}$ for eight, three and one hour periods. The mean plasma IRI levels at $60 \mathrm{~min}$ after beginning of intravenous glucose injection was decreased. In the case of eight hour infusion, the mean insulin response was the smallest $(\mathrm{p}<0.05)$. But the group of one hour infusion, was not decreased insulin levels. (Fig. 2, 3).

Insulinogenic index $(\Delta \mathrm{IRI} / \Delta \mathrm{BS})$ at $60 \mathrm{~min}$ after glucose administration, showed significant differences between the control group and those groups in which insulin was infused for three and eight hours (Fig. 4). And there was no significant difference between the control and the case of one hour infusion. As shown in Figure 5, the disappearance rates of 

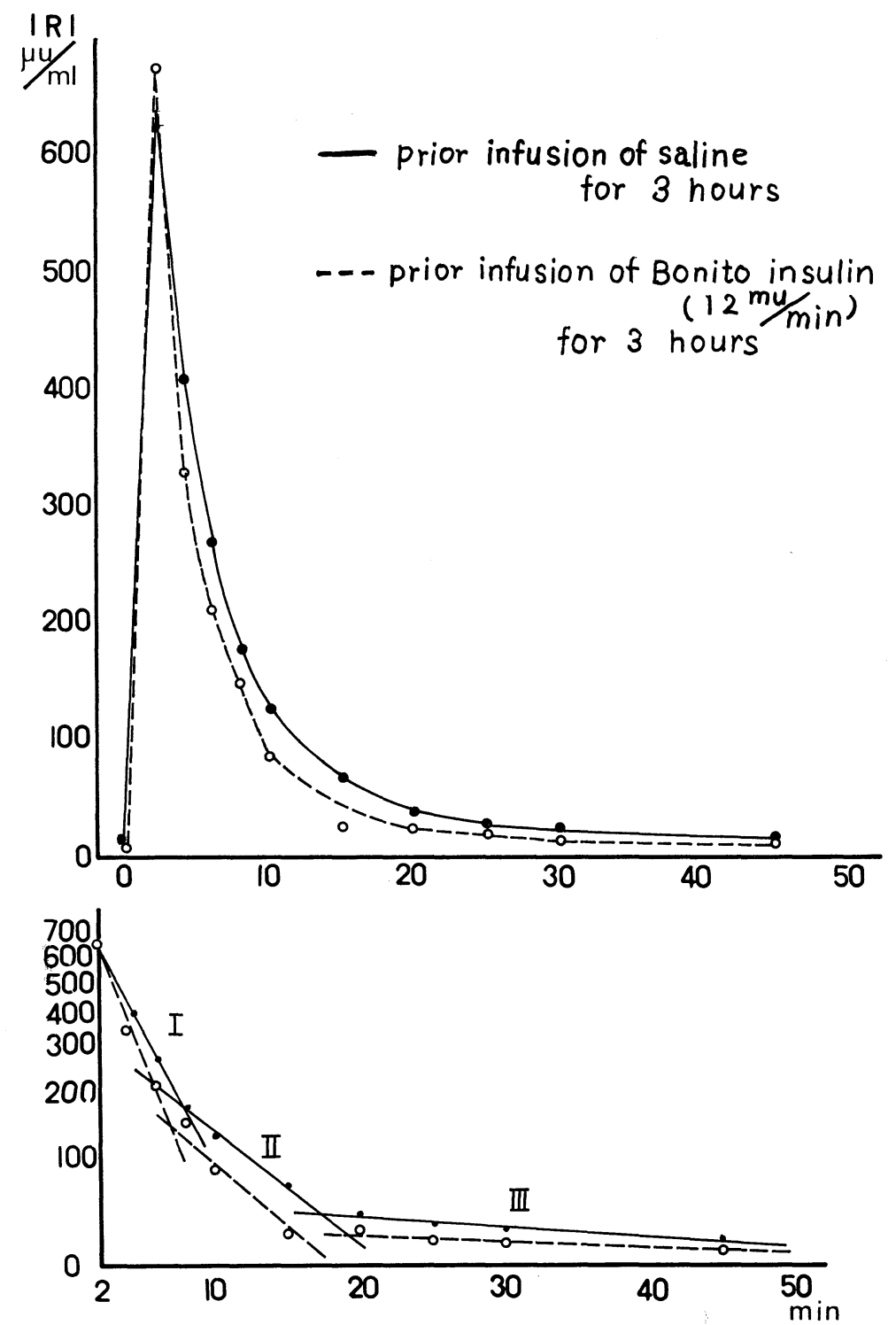

Fig. 5. Effect of prior infusion of bonito insulin on disappearance rate rapidly injected porcine insulin. Three subjects served as their own control. Bonito insulin was infused in a dose of $12 \mathrm{mU} / \mathrm{min}$ at a constant flow rate of $0.5 \mathrm{~m} l$ per min for three $\mathrm{hr}$, and followed by $3 \mathrm{U}$ of porcine insulin which was injected rapidly into the antecubital vein. As a control, each subject was studied, except a saline infusion was substituted for the prior administration of bonito insulin. 
immunoreactive insulin did not shown any significant difference between saline treated subjects and those who had received an infusion of bonito insulin prior to the rapid injection of porcine insulin.

\section{Discussion}

It has been an object of controversy whether a negative feedback regulation operates on insulin secretion through some intermediate substance or thourgh insulin itself. Short feedback control of secretion has been well known for ACTH (Kitay et al., 1959; Sussman et al., 1964; Betes et al., 1964; Sakuma \& Knobil, 1970; Kobayashi \& Kato, 1968; Török, 1964) and HGH (Sussman et al., 1964; Betes et al., 1964; Sakuma \& Knobil, 1970; Kobayashi \& Kato, 1968; Török, 1964). A few in vitro and in vitro experiments have been conducted in an attempt to solve this problem in insulin secretion.

Some found evidence for a feedback mechanism, but only after adding exogenous insulin at very high concentrations including $2 \mathrm{mU} / \mathrm{ml}$ (Loubatieres et al., 1968) and 10 $\mathrm{mU} / \mathrm{m} l$ (Frerichs et al., 1965). On the other hand, some investigators found no inhibition of insulin secretion by insulin. Grodsky reported that no inhibition of insulin on insulin secretion could be detected using isolated perfused rat pancreas and a high concentration of fish insulin (Grodsky et al., 1968b; Grodsky, 1968a). We found that the systemic infusion of small doses of bonito resulted in an inhibition of glucose-induced insulin secretion in man. In the present work, all experiments were performed with infusions of bonito insulin at concentrations of $12 \mathrm{mU} /$ $0.5 \mathrm{ml} / \mathrm{min}$ and $6 \mathrm{mU} / 0.5 \mathrm{ml} / \mathrm{min}$, for these doses of bonito insulin had no effect on the blood sugar levels in our preliminary experiments. The mean blood sugar level in the group of saline treated subjects was not significantly different from that in the groups of subjects who had received insulin.
The inhibitory effect seems not related to any possible stress in experimental situation.

When the insulin curve after glucose infusion in insulin treated subjects was compared to that in the saline groups, it became evident that the biphasic pattern of serum insulin was less marked in the former group. The magnitude of IRI response after glucose administration following $8 \mathrm{hr}$ infusion of insulin was smaller than the produced by the $3 \mathrm{hr}$ infusion. But there was no significant difference between the glucose-induced insulin secretion following one hr of sustained infusion of bonito insulin and that following infusion of saline. This indicates that a high circulating level of exogenous insulin for a prolonged period of time is necessary for development of inhibition of glucose induced insulin response. These results show that exogenous insulin infused for a prolonged period inhibits endogenous insulin secretion. It remains to be established whether the feedback mechanism is direct (Sodoyez et al., 1969; Loubatieres et al., 1968; Frerichs et al., 1965) or indirect (Logothetopoulos et al., 1965; Malaisse \& Malaisse-Lagae, 1969).

It is very important and interesting that there is a lag time in this feedback mechanism. The prolonged infusion of exogenous insulin in subjects might stimulate release of neurohumoral factors (Coore \& Randle, 1964; Wong et al., 1967; Porte et al., 1966) which inhibit the glucose-stimulated insulin release. Further experiments are necessary to confirm the physiological significance of this mechanism in vivo. Direct measurements of insulin in the pancreatic vein and studies on the effect of epinephrine are required to elaborate the details of the feedback mechanism.

\section{Acknowledgments}

We thank Professor K. Shizume and Dr. A. Kaneto., Dr. Y. Tasaka, Dr. N. Ohsawa for their support and encouragement. The generous supply of bonito insulin for Dr. Y. Koga of Shimizu Seiyaku Company is gratefully acknowledged. 


\section{References}

Berson, S. A. and R. S. Yalow (1959). J. Clin. Invest. 38, 2017.

Best, C. H. and R. E. Haist (1941). J. Physiol. 100, 142.

Betes, R. W. S. Milkovic and M. M. Garrison (1964). Ibid. 74, 714.

Chu, P. C. and C. J. Goodner (1968). Endocrinology 82, 296.

Coore H. G. and P. J. Randle (1964). Biochem. J. 39, 66.

Falkmar, S. and S. Whson (1967). Diabetologia 3, 519.

Frerichs, H., Reich, U. and Creutzfeldt, W. (1965). Klin. Wochenshrift 43, 136.

Grodsky, G. M. (1965). Diabetes 14, 396.

Grodsky, G. M. (1968a). Acta. Diab. Lat. 65, 239.

Grodsky, G. M., L. L. Bennett, D. L. Curry and J. J. Rodrigo (1968b). Mechanism and Regulation Insulin Secretion. Case Ed. Ponte. Milano, p. 140.

Hagedorn, H. O. and B. N. Jensen (1923). Biochem. Z. 139, 46.

Hahn, H. J. and R. Micheal (1971). J. of Clin. Invest. 50, 98.

Hellman, B. and A. Lernmark (1969). Ibid. 84, 1848.

Iversen, J. and D. W. Miles (1971). Diabetes 20, 1.

Kitay, J. I., D. A. Holub and J. W. Jailar (1959). Endoclinology 64, 465.

Kobayashi, T. and S. Kato (1968). The Saishin-Igaku 23, 1037. (In Japanese)

Logothetopoulos, J., J. K. Davidson, R. E. Haist and C. H. Best (1965). Diabetes 14, 493.
Loubatieres, A., M. M. Mariani and J. Chapel (1968). CR Acad. Sci. (Paris) Ser D. 226, 2245.

Malaisse, W. J., Malaisse-Lagae, P. E. Lacy and P. H. Wright (1967). Proc. Soc. exp. Biol. 124, 497.

Malaisse, W. and F. Malaisse-Lagae (1969). Diabetologia 5, 349.

Morgan, C. R. and A. Lazarow (1963). Diabetes $\mathbf{1 2}, 115$.

Orskov, H. and N. J. Christensen (1969). Diabetes 18, 653.

Porte, D., A. L. Graber, T. Kuzuya and R. H. Williams (1966). J. Clin. Invest. 45, 228.

Sakuma, M. and E. Knobil (1970). Ibid. 86, 890.

Samols, E. and J. A. Ryder (1961). J. Clin. Invest. 40, 2092.

Samols, E. and D. Bilkus (1964). Proc. Soc. exp. Biol. (N. Y.) 115, 79.

Sando, H., Y. Kanazawa and T. Kuzuya (1970). Am. J. of Physiol. 218, 1357.

Sodoyez, J. C., F. Sodoyez-Goffauy and P. P. Foá (1964). The Structure and Metabolism of the pancreatic Islets. Wenner-Gren Center international Symposium Series. 16, 445.

Sodoyez, J. C., F. Sodoyez-Goffauy and P. P. Foá (1969). Proc. Soc. exp. Biol. Med. 130, 568.

Sussman, L., L. Lbrik and G. W. Clayton (1964). Ibid. 74, 714.

Török, B. (1964). Acta. Anta. 59, 84.

Wong, K. K., S. Symckowics, M. S. Staub and I. I. A. Tabacknick (1967). Life Sci. 6, 2285.

Yalow, R. S. and S. A. Berson (1964). New Engl. J. Med. 270, 1171. 